\title{
Vitamin C Inhibits Aggravated Eryptosis by Hydrogen Peroxide in Glucose-6- Phosphated Dehydrogenase Deficiency
}

\author{
Feng Shan ${ }^{\mathrm{a}}$ Rui Yang ${ }^{\mathrm{b}}$ Tiemei Jic $^{\mathrm{c}}$ Fengjun Jiao $^{\mathrm{d}}$ \\ aDepartment of Laboratory, Affiliated Hospital of Jining Medical University, Shandong, bepartment \\ of Hyperbaric Oxygen, Yidu Central Hospital of Weifang City, Shandong, 'Department of Laboratory, \\ The Third People's Hospital of Heze City, Shandong, IIntensive Care Unit, The First People's Hospital of \\ Xianyang City, Xiyang, China
}

\section{Key Words}

G6PD deficiency $\bullet$ Eryptosis $\bullet$ Hydrogen peroxide $・$ Vitamin $C \cdot$ Anemia $・$ Malaria

\begin{abstract}
Background/Aims: The study was aimed to investigate if vitamin $C$ could exert protective effects on development of eryptosis caused by glucose-6-phosphate dehydrogenase (G6PD) deficiency and hydrogen peroxide. Methods: Isolated erythrocytes with different G6PD activity (normal or deficient) were divided into various groups treated by either Vitamin $\mathrm{C}_{\text {or }} \mathrm{H}_{2} \mathrm{O}_{2}$. Phosphatidylserine (PS) extroversion rate was detected by Annexin V binding. The intracellular $\mathrm{Ca}^{2+}$ concentration was detected by Fluo3-fluorescence, and western blot was used to detect the expression of apoptosis factor caspase 3. Results: Compared with the blank group, the PS extroversion rate $(P<0.001)$, intracellular $\mathrm{Ca}^{2+}$ concentration $(P<0.001)$ and active caspase 3 expression level $(P<0.05)$ of erythrocytes significantly increased after treatment of $0.05 \%$ $\mathrm{H}_{2} \mathrm{O}_{2}$. Then the index of eryptosis significantly decreased after erythrocytes were treated with Vitamin C $(1 \mathrm{mg} / \mathrm{ml})$ for 30 min (all $P<0.05)$. The decline in erythrocytes with G6PD normal activity was more significant than those with G6PD deficiency. Conclusion: Vitamin $C$ could effectively inhibit the eryptosis contributed by $\mathrm{H}_{2} \mathrm{O}_{2}$ oxidative stress, and the suppression on eryptosis with G6PD normal activity was more effective than that with G6PD deficiency.
\end{abstract}

(C) 2016 The Author(s)

Published by S. Karger AG, Basel

\section{Introduction}

Glucose-6-phosphate dehydrogenase (G6PD) deficiency (OMIM 305900) is a hereditary disorder featured by hemolytic erythrocyte enzyme defect, leading to around 400 million cases worldwide [1]. G6PD is a crucial rate-limiting enzyme in the pentose phosphate pathway which contributes much to maintaining intracellular reducing state [2]. The 


\section{Cellular Physiology Cell Physiol Biochem 2016;39:1453-1462 and BiOChemistry \begin{tabular}{l|l} 
DOI: $10.1159 / 000447848$ & Published online: September 09, 2016 \\
(c) 2016 The Author(s). Published by S. Karger AG, Basel \\
wwer.com/cpb
\end{tabular} \\ Shan et al.: Vitamin C Protects G6PD Deficiency Erythrocytes}

underlying mechanism lies in its facilitating catalyzation of glucose-6-phosphate (G6P) into G6P lactone and biosynthesis of nicotinamide adenine dinucleotide phosphate (NADPH) [2]. G6PD deficiency is primarily caused by genetic mutations and totally 206 mutation sites have been discovered (http://www.hgmd.org), such as G6PD Canton (1376G>T), G6PD Kaiping (1388G>A), G6PD Gaohe (95A>G), G6PD Quing Yuan (392G>T), "Chinese-5" (1024C>T) and G6PD Viangchan $(1311 \mathrm{C}>\mathrm{T})$. Besides, the above mutations were prevalent in south of China such as Guangdong, Guangxi and Yunnan Province [3, 4].

Since erythrocytes differ from nucleus cells in its shortage of cell nucleus and certain organelles (e.g. mitochondria), the pentose phosphate pathway becomes its only way to produce NADPH [5]. As a result, compared with normal nucleus cells, erythrocytes seem to be more susceptible to oxidative stress, and eryptosis, the molecular programming process characterized by cell suicide, could be more readily induced [6]. Virtually, erythrocytes with G6PD deficiency that can hardly synthesize NAPDH would accelerate the progress of eryptosis [7]. The morphological features of eryptosis include shrinking of red blood cell (RBC) membrane and phosphatidylserine (PS) exposure on the surface of RBCs [8]. Of note, eryptosis has been confirmed to be associated with inherent mechanisms as follows: overload of intracellular $\mathrm{Ca}^{2+}$ concentration, formation of ceramide, activation of caspase and excitation of calpain $[9,10]$. Thus, it is hypothesized that the eryptosis stimulated by oxidative stress might be correlated with the above actions. Furthermore, as excessive eryptosis is likely to cause such disorders as anemia, diabetes mellitus, renal insufficiency, and hemolyticuremi syndrome, exploration of the potential treatments becomes increasingly urgent [11]. It has been demonstrated that pharmalogical doses of Vitamin $\mathrm{C}$ would relieve hemolysis within patients that suffered from G6PD deficiency [12-14]. Nonetheless, it was undeniable that over-dose Vitamin C could also contribute to aggravated haemolysis of G6PD-deficient erythrocytes, as reported in both case reports and mechanism researches [15-17]. Thus, this study was intended to investigate the eryptosis conditions among the population with G6PD deficiency or nomal activity habituated in Daidehong prefecture of Yunnan province and to explore the inherent mechanisms with in-vitro erythrocytes that were treated with proper concentrations of Vitamin $\mathrm{C}$ and hydrogen peroxide.

\section{Materials and Methods}

\section{Clinical specimens}

Blood samples used in this study were collected from the First People's Hospital of Xianyang City. This study was approved by the Ethics Committee of the First People's Hospital of Xianyang City and all methods conducted were complied with relevant guidelines. Written informed consent was obtained from each participant before blood collection. EDTA anticoagulative tubes (BD, USA) were used to collect peripheral vein blood samples from 22 participants, and the samples were stored at $4^{\circ} \mathrm{C}$.

Enzyme assay

The WHO standard method [18, 19] along with the improved G6PD/6PGD ratio assay [20] was considered as the benchmark for G6PD activity assessment. Specifically, optical densities (ODs) of G6P (S1) and 6PG (S2) were determined with application of UV-2100 ultraviolet spectrophotometer (Shimadzu, Japan) at the wavelength of $450 \mathrm{~nm}$. G6PD activity was calculated as the following formula: S1/S2. The reagents of $\beta$-NADP, G6P-Na and 6PG-Na were all purchased from Sigma Corporation.

\section{Genotyping}

TIANamp Blood DNA Kit (TIANGEN, Beijing, China) was used to extract genome DNA. As suggested by the G6PD genome sequence data, the primers for amplification of 11 regions on G6PD exon and intron fragments were designed and synthesized by Primer 5.0 software $[3,21,22]$. The $25 \mu$ l reaction system is comprised of 1.25 U Taq Polymerase (TaKaRa), $2 \times$ Premix buffer (TaKaRa), $0.2 \mu$ M primers (Sangon Biotech) and 200 ng genomic DNA. The reaction was carried out under the following conditions: predegeneration at $94^{\circ} \mathrm{C}$ for $3 \mathrm{~min}$; degeneration at $94^{\circ} \mathrm{C}$ for $30 \mathrm{~s}$, annealing at $60^{\circ} \mathrm{C}$ for $30 \mathrm{~s}$, extending at $72^{\circ} \mathrm{C}$ for $1 \mathrm{~min}$, 


\section{Cellular Physiology Cell Physiol Biochem 2016;39:1453-1462 \\ \begin{tabular}{l|l|l} 
and Biochemistry $\begin{array}{l}\text { DOI: 10.1159/000447848 } \\
\text { Published online: September 09, } 2016\end{array}$ & $\begin{array}{l}\text { (c) The Author(s). Published by S. Karger AG, Basel } \\
\text { wwwkargercom/cpb }\end{array}$
\end{tabular}}

Shan et al.: Vitamin C Protects G6PD Deficiency Erythrocytes

30 cycles; extending at $72^{\circ} \mathrm{C}$ for $10 \mathrm{~min}$. The PCR amplification products were detected by bidirectional DNA sequencing (Sangon Biotech). The sequencing results were compared with the sequence data in the database and analyzed with Chromas and Clustalx.

\section{Erythrocytes isolation and chemical treatment}

A total of 22 samples were divided into G6PD normal group (male 11) and G6PD deficiency group (male 9, female 2). Flesh blood was centrifuged at 1000g for $20 \mathrm{~min}$ at room temperature and plasma containing blood platelets and white cells was carefully removed. Isolated erythrocytes were washed twice by Ringer solution and the erythrocytes hematocrit was set for 40\%. Ringer solution (in mM) was prepared in the laboratory according to the formula: $125 \mathrm{NaCl}, 5 \mathrm{KCl}, 1 \mathrm{MgSO}_{4}, 32 \mathrm{~N}$-2-hydroxyethylpiperazine$\mathrm{N}$-2-ethanesulfonic acid (HEPES), 5 glucose, $1 \mathrm{CaCl}_{2}$, $\mathrm{pH} 7.4$ at $37^{\circ} \mathrm{C}$ [23]. Subsequently, the mixture was maintained at $\mathrm{pH} 7.4$ and at $37^{\circ} \mathrm{C}$. Erythrocytes in the two groups were pretreated with Ringer solution (Blank group) or Vitamin C (1 mg/ml, VC group), and then incubated at $37^{\circ} \mathrm{C}$ for $30 \mathrm{~min}$. Since vitamin $\mathrm{C}$ affects erythrocytes in a concentration-dependent manner, previous documents were referred to and preparing experiments were conducted so that the protective effects of vitamin $\mathrm{C}$ on erythrocytes could be ensured [19]. Erythrocytes were washed twice by Ringer solution again. The erythrocytes in the treatments groups above were treated with Ringer solution or hydrogen peroxide $\left(\mathrm{H}_{2} \mathrm{O}_{2}, 0.5 \%\right)$ for 30 min at $37^{\circ} \mathrm{C}$. Finally, erythrocytes samples were randomly divided into 8 groups (Fig. 1): G6PD normal/Blank group (only treated with Ringer solution), G6PD normal/VC group (treated with Ringer solution and Vitamin C), G6PD normal/ $\mathrm{H}_{2} \mathrm{O}_{2}$ group (treated with Ringer solution and $\mathrm{H}_{2} \mathrm{O}_{2}$ ), G6PD normal/VC $+\mathrm{H}_{2} \mathrm{O}_{2}$ group (treated with Vitamin $\mathrm{C}$ and $\mathrm{H}_{2} \mathrm{O}_{2}$ ), G6PD deficiency/Blank group (only treated with Ringer solution), G6PD deficiency/ VC group (treated with Ringer solution and Vitamin C), G6PD deficiency/ $\mathrm{H}_{2} \mathrm{O}_{2}$ group (treated with Ringer solution and $\mathrm{H}_{2} \mathrm{O}_{2}$ ), G6PD deficiency/VC+ $\mathrm{H}_{2} \mathrm{O}_{2}$ group (treated with Vitamin $\mathrm{C}$ and $\mathrm{H}_{2} \mathrm{O}_{2}$ ).

\section{Ascorbic acid (AA) detection}

About $1 \mathrm{ml}$ methanol (volume fraction: 70\%) with addition of $1 \mathrm{mmol} / \mathrm{L}$ ethylene diamine tetraacetic acid (EDTA) was prepared to treat cells for $10 \mathrm{~min}$. Subsequently, the extraction liquid containing AA was determined with application of ascorbic acid assay kit (BioVision corporation, America).

PS extroversion rate detection

Erythrocytes were suspended in $100 \mu$ l Annexin-V binding buffer and cell concentration was adjusted to the level of $1 \times 10^{6}$ per ml. Then, $5 \mu$ FITC-Annexin- $V$ was added to cell suspension, gently mixed and stored in dark at room temperature for $15 \mathrm{~min}$. After that, $400 \mu \mathrm{l}$ Annexin-V binding buffer was added to the mixture so that the cells resuspended and then the mixture was analyzed using flow cytometer (BECKMANCOULTER). The light path was calibrated with fluorescent microsphere to ensure the variable coefficient $(\mathrm{CV})<2 \%$ in the flow cytometer. FL-1 fluorescence signal (excitation wavelength at $488 \mathrm{~nm}$, emission wavelength at $525 \mathrm{~nm}$ ) of 10,000 erythrocytes was detected in the cell suspension. FL-1 fluorescence signal indicated the PS extroversion rate.

Fig. 1. Treatment-group assignment of erythrocytes samples.

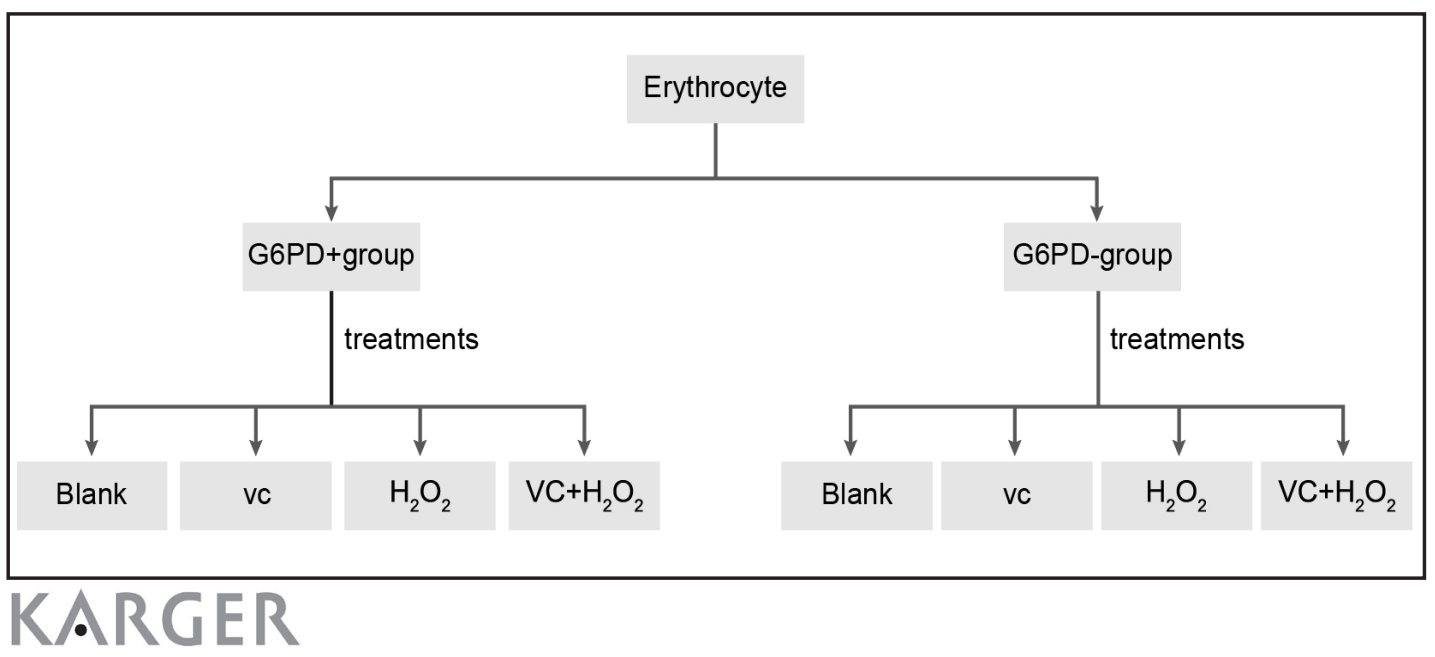




\section{Cellular Physiology Cell Physiol Biochem 2016;39:1453-1462

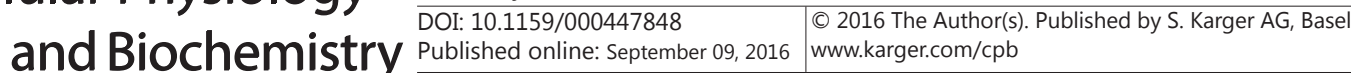 \\ Shan et al.: Vitamin C Protects G6PD Deficiency Erythrocytes}

Intracellular $\mathrm{Ca}^{2+}$ concentration detection

Erythrocytes were suspended in $1 \mathrm{ml}$ Ringer solution which adjusts the concentration to the level of $1 \times 10^{6} / \mathrm{ml}$. $5 \mu$ Fluo-3/AM buffer was added to cell suspension, mixed gently and stored in dark for 25 $\min$ at $37^{\circ} \mathrm{C}$. After the supernatants were removed by centrifugation, erythrocytes were washed twice with Ringer solution and $1 \mathrm{ml}$ Ringer solution was applied to suspend cells for detection. The light path was calibrated with fluorescent microsphere to ensure variable coefficient (CV) $<2 \%$ in the flow cytometer. The FL-1 fluorescence signal of 10,000 erythrocytes was detected.

Western blot analysis

A total of $1 \times 10^{6}$ cells were collected from each group, and proteins were extracted using RIPA Lysis Buffer. The proteins expression levels were detected using the BCA method. Equal quantity of proteins in each group was resolved on 10\% SDS PAGE (polyacrylamide gel electrophoresis) and then transferred to PVDF (polyvinylidenefluoride) membrane. Moreover, 5\% skim milk was used for blocking for $1 \mathrm{~h}$ at room temperature. Subsequently, membrane was incubated with primary antibody rabbit anti-caspase-3 (1:1000) at $4^{\circ} \mathrm{C}$ overnight. After the membrane was washed by TBST, the HRP (horse radish peroxidase) labeled as the second goat-anti-rabbit antibody (1:5000) was used as probe for combination. The signal was normalized to the internal reference GAPDH (1:5000) and was semi-quantitatively analyzed through Gel-Pro Analyzer 4.0 software.

\section{Statistical Analysis}

Data was presented as mean \pm standard deviation (SD), and SPSS 18.0 software was used to perform the statistical analysis. The comparison between two groups was assessed by the t-test, while the difference among multiple groups was tested by one-way ANOVA (statistical significant: $P$ value $<0.05$ ). R language software (qq norm) was carried out to figure out if relevant values were in accordance with normal distribution. If variances of values were not homogeneous despite their conforming to normal distribution, the results of student's t test would be corrected with welch method. Besides, the results that did not conform to the normal distribution were compared with usage of nonparametric rank sum test.

\section{Results}

\section{G6PD mutation detection}

The WHO standard were adopted as the classification criteria: a zero enzyme activity with chronic non-spherocytic hemolytic anemia was identified as clinical class I; an enzyme activity between $0 \%$ and $10 \%$ with hemolytic anemia and occasional favism or medicines intake was defined as clinical class II; an enzyme activity between $10 \%$ and $60 \%$ without hemolytic anemia was defined as clinical class III; an enzyme activity between $60 \%$ and $100 \%$ without hemolytic anemia was identified as clinical class IVa; an enzyme activity between $100 \%$ and $150 \%$ without hemolytic anemia was identified as clinical class IVb; an enzyme activity above $200 \%$ without hemolytic anemia was defined as clinical class V. Six point variants were discovered in 11 G6PD-deficient patients. Some nucleotide changes were consistent with previous study [19] including 392G $\rightarrow \mathrm{T}, 1376 \mathrm{G} \rightarrow \mathrm{T}$, while new changes like $487 \mathrm{G} \rightarrow \mathrm{A}$ were discovered. Details about the correlation between genotype and phenotype correlation in 11 G6PD-deficient patients were shown in Table 1.

\section{PS extroversion rate of erythrocytes}

The PS extroversion rates of suspended erythrocytes were detected using flow cytometry (Fig. 2) and whether the determined figures met normal distribution was judged as shown in Fig. 3. The PS extroversion rate of erythrocytes in the blank or VC group with G6PD normal activity or G6PD deficiency were extremely low without significant difference. The addition of $0.5 \% \mathrm{H}_{2} \mathrm{O}_{2}$ significantly increased the PS extroversion rate compared with the blank group (both $P<0.001$ ). However, the PS extroversion rate of G6PD deficiency erythrocytes was significantly higher than that of G6PD normal erythrocytes $(P<0.001)$. $\mathrm{H}_{2} \mathrm{O}_{2}$ could contribute to PS extroversion on the erythrocytes membrane and erythrocytes 
Table 1. Genotype and phenotype correlations in 11 G6PD-deficient patients. The WHO standard (WHO Scientific Groups 1967) were adopted as the classification criteria: a zero enzyme activity with chronic nonspherocytic hemolytic anemia was identified as clinical class I; an enzyme activity between 0\% and 10\% with hemolytic anemia and occasional favism or medicines intake was defined as clinical class II; an enzyme activity between $10 \%$ and $60 \%$ without hemolytic anemia was defined as clinical class III; an enzyme activity between $60 \%$ and $100 \%$ without hemolytic anemia was identified as clinical class IVa; an enzyme activity between $100 \%$ and $150 \%$ without hemolytic anemia was identified as clinical class IVb; an enzyme activity above $200 \%$ without hemolytic anemia was defined as clinical class V. F, female; M, male

\begin{tabular}{|c|c|c|c|c|c|c|c|c|c|}
\hline Exon & $\begin{array}{c}\text { cDNA } \\
\text { nucleotide change }\end{array}$ & Name & Amino acid change & Class I & Class II & Class III & Class IV & Class V & Total \\
\hline 5 & $392 \mathrm{G} \rightarrow \mathrm{T}$ & G6PD Quing Yuan & p.131Gly $\rightarrow$ Val & 0 & 0 & 1 (M) & 0 & 0 & 1 \\
\hline 6 & $487 \mathrm{G} \rightarrow \mathrm{A}$ & G6PD Mahidol & p.163Gly $\rightarrow$ Ser & 0 & 0 & $2(M)$ & 0 & 0 & 2 \\
\hline 11 & $1311 \mathrm{C} \rightarrow \mathrm{T}$ & G6PD Viangchan & & 0 & 0 & 0 & $1(F)$ & 0 & 1 \\
\hline 12 & $1376 \mathrm{G} \rightarrow \mathrm{T}$ & G6PD Canton & p.459Arg $\rightarrow$ Leu & 0 & $3(1 \mathrm{M}, 2 \mathrm{~F})$ & 0 & 0 & 0 & 3 \\
\hline \multirow[t]{3}{*}{12} & $1388 \mathrm{G} \rightarrow \mathrm{A}$ & G6PD Kaiping & p.463Arg $\rightarrow$ His & 0 & $3(\mathrm{M})$ & 0 & 0 & 0 & 3 \\
\hline & Mutant allele unknown & & & 0 & $1(\mathrm{M})$ & 0 & 0 & 0 & 1 \\
\hline & Total & & & 0 & 2 & 8 & 1 & 0 & 11 \\
\hline
\end{tabular}

Fig. 2. Phosphatidylserine (PS) extroversion rate (\%) of erythrocytes with normal G6PD activity or G6PD deficiency in different treatment groups detected by flow cytometry. G6PD+represented G6PD normal activity, G6PD- represented G6PD deficiency. ${ }^{* * *} P<0.001$.
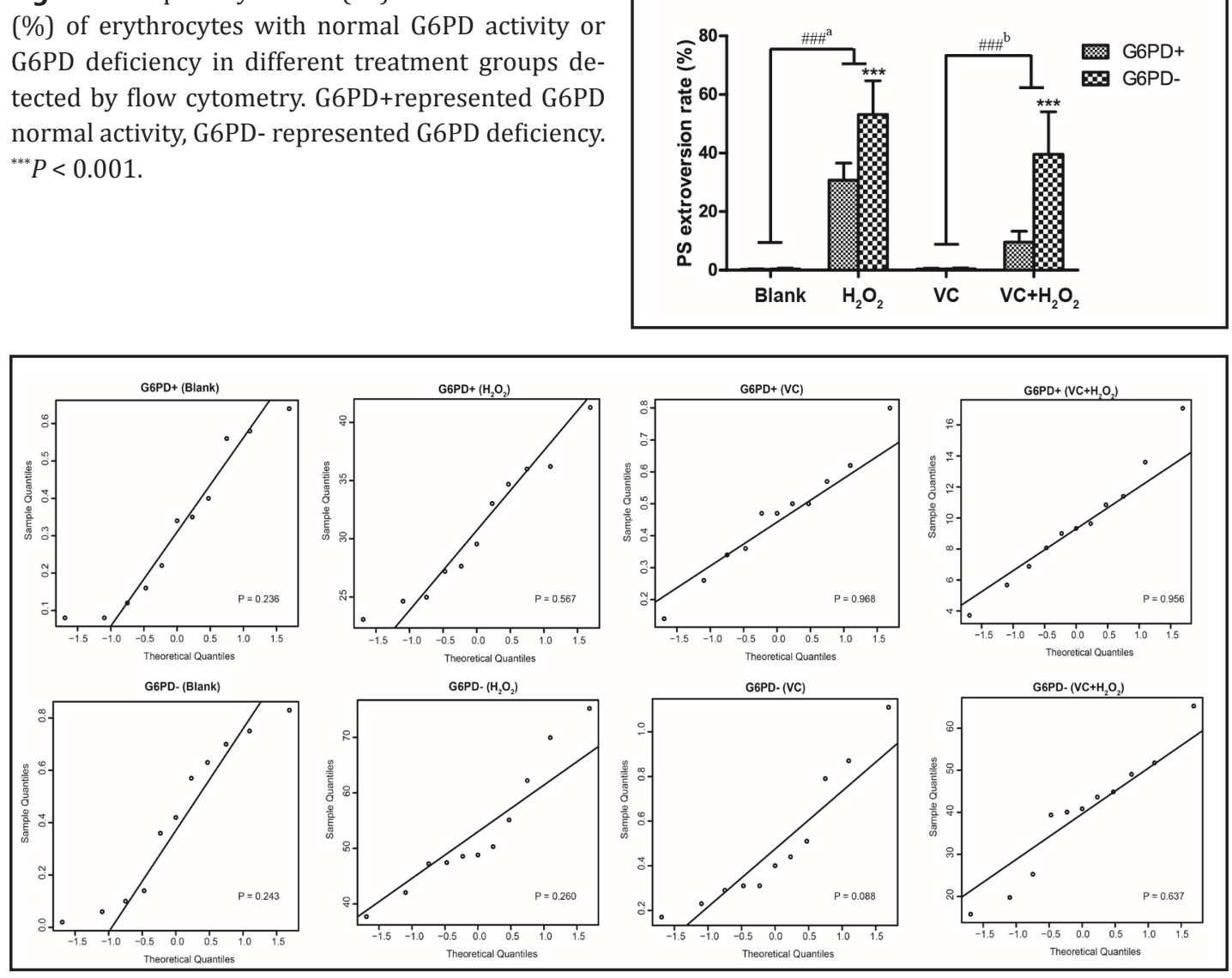

Fig. 3. Normal distribution results regarding PS extroversion rate of 8 treatment groups.

with G6PD deficiency may be more sensitive to $\mathrm{H}_{2} \mathrm{O}_{2}$ than erythrocytes with normal G6PD. Moreover, the PS extroversion rate in the $\mathrm{VC}+\mathrm{H} 2 \mathrm{O} 2$ group was significantly higher than that in the VC group $(P<0.001)$, while it was significantly lower than that in the $\mathrm{H}_{2} \mathrm{O}_{2}$ group $(P<$ 0.01 ), suggesting that Vitamin $C$ could reverse the effect of oxidation stress on erythrocytes 
Fig. 4. The concentration of intracellular $\mathrm{Ca}^{2+}$ in erythrocytes with normal G6PD activity or G6PD deficiency in different treatment groups detected by flow cytometry. G6PD+represented G6PD normal activity, G6PD- represented G6PD deficiency. ${ }^{*} P<0.05$,

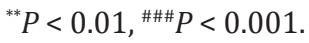
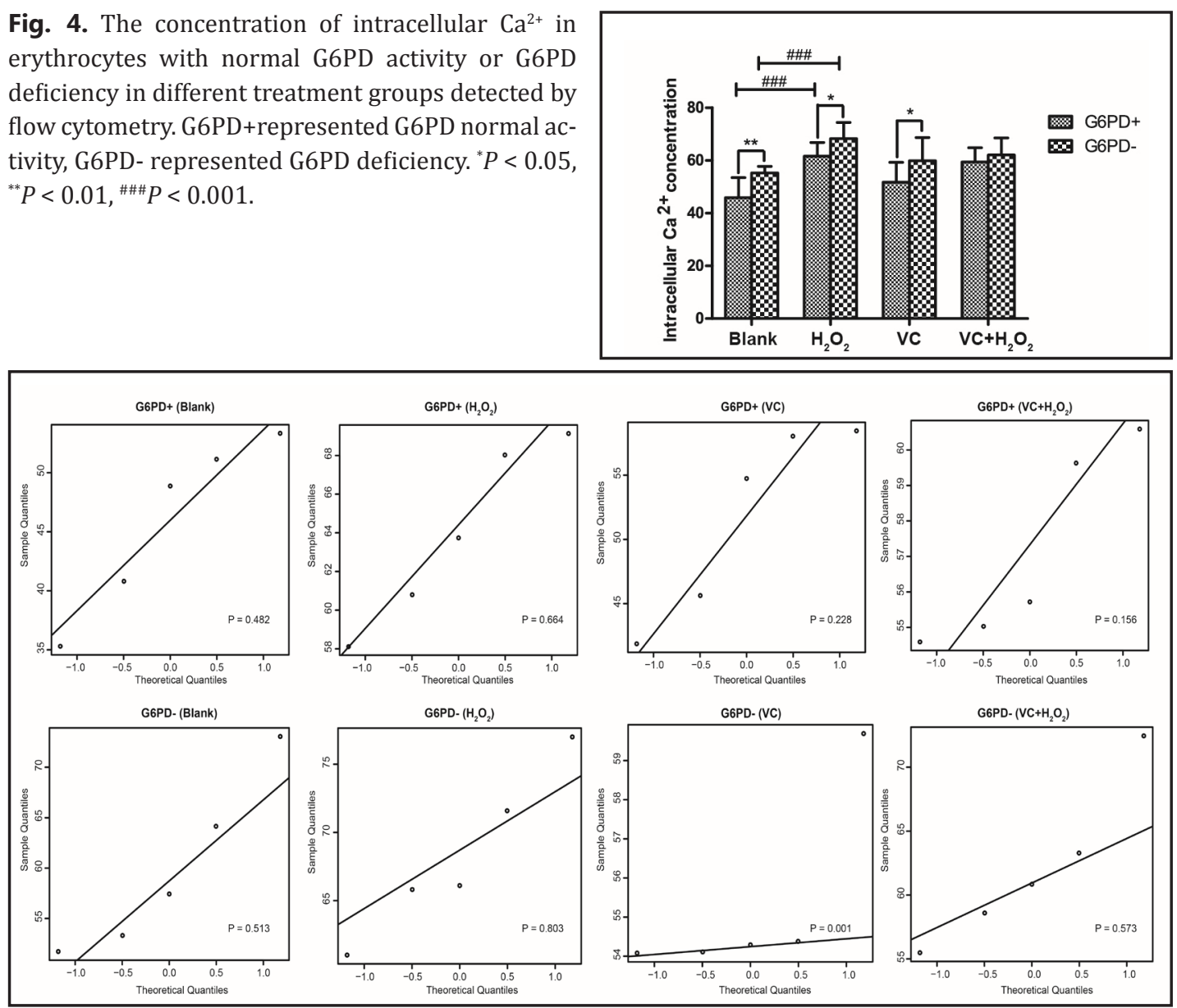

Fig. 5. Normal distribution results regarding intracellular $\mathrm{Ca}^{2+}$ concentration of 8 treatment groups.

triggered by $\mathrm{H}_{2} \mathrm{O}_{2}$. Interestingly, the PS extroversion rate of G6PD deficiency erythrocytes was significantly higher than that of G6PD normal erythrocytes in the $\mathrm{VC}+\mathrm{H} 2 \mathrm{O} 2$ group $(P<$ $0.001)$.

\section{Intracellular $\mathrm{Ca}^{2+}$ concentration in erythrocytes}

As shown by Fig. 4, the concentration of intracellular $\mathrm{Ca}^{2+}$ in the $\mathrm{H}_{2} \mathrm{O}_{2}$ group was significantly increased compared to the blank group $(P<0.001)$. No significant difference was detected between the blank and VC group. The intracellular $\mathrm{Ca}^{2+}$ concentration in the $\mathrm{VC}+\mathrm{H}_{2} \mathrm{O}_{2}$ group had a declining tendency in comparison to the $\mathrm{H}_{2} \mathrm{O}_{2}$ group with no statistical significance $(P>0.05)$, suggesting that the intracellular $\mathrm{Ca}^{2+}$ concentration was not only associated with the treatment of $\mathrm{H}_{2} \mathrm{O}_{2}$ or Vitamin $\mathrm{C}$ but also related to the G6PD activity. Furthermore, the intracellular $\mathrm{Ca}^{2+}$ concentration of erythrocytes with G6PD deficiency was significantly higher than those with G6PD normal activity in the blank $(P<0.01), \mathrm{H}_{2} \mathrm{O}_{2}(P<$ $0.05)$ and VC group $(P<0.05)$ after adjustment (Fig. 5).

\section{Caspase 3 expression detected by western blot}

As suggested by Fig. 6, results from western blot indicated that inactive caspase 3 expression remained stable in all groups. In contrast, the active caspase 3 expression levels significantly increased in the $\mathrm{H}_{2} \mathrm{O}_{2}$ group compared to the blank group $(P<0.05)$ (Fig. 7). And the active caspase 3 expression levels in the $\mathrm{VC}+\mathrm{H}_{2} \mathrm{O}_{2}$ group were significantly lower than those in the $\mathrm{H}_{2} \mathrm{O}_{2}$ group $(P<0.05)$. No significant difference was found between the blank and VC group. The active caspase 3 expression level of erythrocytes with G6PD deficiency was significantly higher than that of erythrocytes with G6PD normal activity 
Fig. 6. The expression level of active caspase 3 in erythrocytes of different groups detected by western blot. iCaspase 3 represents inactive Caspase 3, weighing for $32 \mathrm{kD}$; aCaspase 3 represents active caspase 3, weighing for $20 \mathrm{kD}$; GAPDH, $37 \mathrm{kD}$, used as internal reference. G6PD+ represented G6PD normal activity, G6PD- represented G6PD deficiency.

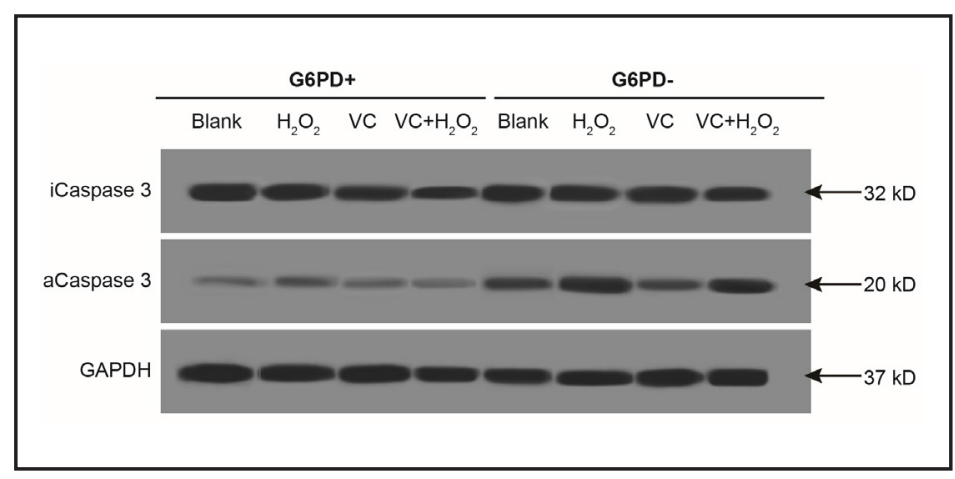

Fig. 7. The expression levels of active caspase 3 (aCaspase3) relative to GAPDH in erythrocytes of different groups detected by western blot. ${ }^{*} P<0.05$, comparison with blank group; ${ }^{\#}<0.05$, comparison with $\mathrm{H}_{2} \mathrm{O}_{2}$ group.

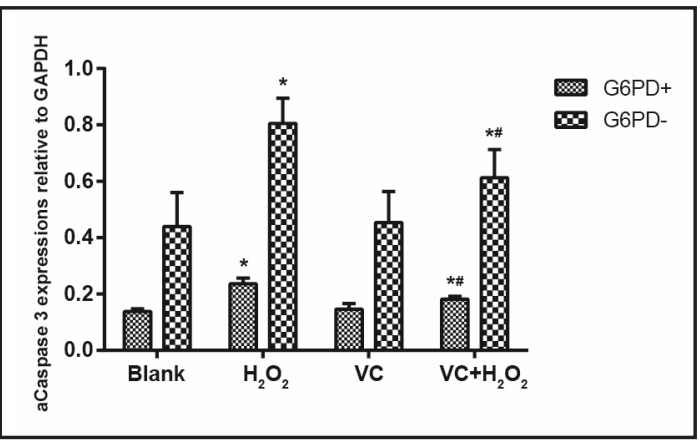

especially in the $\mathrm{H}_{2} \mathrm{O}_{2}$ and $\mathrm{VC}+\mathrm{H}_{2} \mathrm{O}_{2}$ group (both $P<0.05$ ). As a result, $\mathrm{H}_{2} \mathrm{O}_{2}$ could contribute to eryptosis and erythrocytes with G6PD deficiency were more prone to oxidative stress in comparison to erythrocytes with normal G6PD. Vitamin $C$ could effectively inhibit the eryptosis contributed by $\mathrm{H}_{2} \mathrm{O}_{2}$.

\section{Discussion}

Since the pentose phosphate pathway was the only source which produced NADPH in erythrocytes, the defense system that tackled oxidative stress in erythrocytes was highly dependent on the activity of G6PD enzyme and erythrocytes in G6PD deficient patients could be more prone to oxidative stress. Specifically, NADPH has been considered as a necessary substrate within the anti-oxidant system for translating oxidized glutathione into reduced glutathione and activating catalase through allosteric effects [24]. Hence, G6PD activity deficiency was suspected to inhibit the antioxidant effect of erythrocytes by attenuating the level of NADPH. The hypothesis has partly been confirmed by our study results that G6PD+ carriers were less susceptible to $\mathrm{H}_{2} \mathrm{O}_{2}$ than G6PD- carriers, and G6PD- carriers were harder to recover from damage of $\mathrm{H}_{2} \mathrm{O}_{2}$ after treatment of vitamin $\mathrm{C}$.

In fact, whether the eryptosis induced by $\mathrm{H}_{2} \mathrm{O}_{2}$ in erythrocytes was intrinsic or extrinsic still remained unconclusive. We considered this eryptosis to be mostly extrinsic if "intrinsic" was defined as eryptosis caused by mutations of DNAs and "extrinsic" was defined as eryptosis induced by damage of cellular components. Specifically, $\mathrm{H}_{2} \mathrm{O}_{2}$ belonged to reactive oxygen species (ROS) that were produced by erythrocytes in a continuous manner [25]. The ROS could contribute to lipid peroxidation, protein oxidation and rise of met-hemoglobin, malondialdehyde and protein carbonyls within erythrocytes [26]. Besides, hydroxyl radicals transformed from $\mathrm{H}_{2} \mathrm{O}_{2}$ also served to initiate annexin binding in erythrocytes [27]. The above reactions might finally lead to loss of membrane integrity and the so-called hemolysis [28]. Undeniably, ROS might initiate destruction of hereditary materials, since that $\mathrm{H}_{2} \mathrm{O}_{2}$ has been documented to induce DNA fragmentation in fish erythrocytes [27]. Nonetheless, distinct from fish erythrocytes, mature erythrocytes of mammals no longer retained their nuclei [29]. Therefore, whether $\mathrm{H}_{2} \mathrm{O}_{2}$ would lead to DNA degradation within cytoplasm or not was still a challenging issue. 


\section{Cellular Physiology Cell Physiol Biochem 2016;39:1453-1462 \\ \begin{tabular}{ll|l} 
and BiOChemistry Published online: September 09, 2016 & $\begin{array}{l}\text { (c) } 2016 \text { The Author(s). Published by S. Karger AG, Basel } \\
\text { www.karger.com/cpb }\end{array}$
\end{tabular} \\ Shan et al.: Vitamin C Protects G6PD Deficiency Erythrocytes}

Since erythrocytes did not include nuclei, the eryptosis pathway might be dependent on $\mathrm{Ca}^{2+}$ permeability cation pathway, rather than mitochondria-specific NF- $\kappa \mathrm{B}, \mathrm{p} 53$ and STAT3/NFAT pathways [30, 31]. The overload of intracellular $\mathrm{Ca}^{2+}$ concentration activated $\mathrm{K}^{+}$outflow from the potassium channel which furthers contributed to hyperpolarization of cytomembrane and outflow of $\mathrm{Cl}^{-}$. In consequence, cell volumes significantly shrink due to osmotic pressure change and the forward scatter decreases [32]. Besides intracellular $\mathrm{Ca}^{2+}$, activations of caspase and calpain were also involved in eryptosis which modified the structures of cell skeleton [33]. Moreover, eryptosis was also characteristic of microcirculative damages which were contributed by PS eversion of erythrocytes [11]. The extroversion of PS on RBC membranes could also contribute to blood coagulation and thrombogenesis [11]. Then eryptosis would take place if the erythrocytes with PS eversion could not be degraded by phagocytes or liver Kupffer cells with PS receptor [34].

Vitamin C, the could-be treatment for G6PD deficiency, was predominantly taken into erythrocytes in two forms, namely, ascorbic acid (AA) and dehydroascorbic acid (DHA). AA mainly relies on $\mathrm{Na}^{+}$-dependent transporter, while DHA was mediated by glucose transporter (GLTU) $[35,36]$. Besides, DHA has been reported to be reduced to AA at first inside the cell, and it is AA that played key anti-oxidant roles [37, 38]. It was indicated in Fig. 2 that PS extroversion rates of G6PD+ carriers in vitamin C + H2O2 group were significantly ameliorated than those in $\mathrm{H} 2 \mathrm{O} 2$ group, while the trend was not so remarkable with regard to the carriers with G6PD deficiency. It could be explicated by the fact that vitamin $\mathrm{C}$ can promote formation of NAPDH through strengthening the reducing characteristics of NAPDHdependent methemoglobin reductase $[39,40]$. Furthermore, the anti-oxidative ability of vitamin $\mathrm{C}$ cannot be overlooked even though its action concentration is far beyond the natural concentration. For instance, vitamin $C$ could scavenge excessive oxygen free radicals arising from G6PD deficiency or damage of hydrogen peroxide [39, 41]. Besides, vitamin C could also aid in recycling of oxidized vitamin $\mathrm{E}$ in indirect manners [42].

Interestingly, Vitamin $\mathrm{C}$ did not bring down the increased $\mathrm{Ca}^{2+}$ concentration within erythrocytes that was caused by oxidative stress. The distinct tendencies between indicators of PS extroversion rate and $\mathrm{Ca}^{2+}$ concentration could probably be explained by their involvement with dissimilar signaling pathways that were relevant to eryptosis. In particular, oxidative stress was correlated with protein kinase activation, while intracellular $\mathrm{Ca}^{2+}$ concentration was related with phosphatase activation [43]. Vitamin $\mathrm{C}$ was a reagent that was applied to antagonize oxidative stress and could more directly affect protein kinase activation, suggesting that the indirect effects of vitamin $\mathrm{C}$ on intracellular $\mathrm{Ca}^{2+}$ concentration might not be larger than those on actions related with oxidative stress. Besides, caspase levels also displayed remarkable changes between treatments of $\mathrm{H} 2 \mathrm{O} 2$ and vitamin $\mathrm{C}+\mathrm{H}_{2} \mathrm{O}_{2}$, which appeared distinct from $\mathrm{Ca}^{2+}$ concentration. The phenomena could be suspected that vitamin $\mathrm{C}$ might deactivate caspase that was independent of $\mathrm{Ca}^{2+}$ entry [44].

Despite the above achievements, several limitations remain present. Firstly, the sample size in this study is not large enough to draw unbiased conclusions. Secondly, although this study validated the effects of $\mathrm{H}_{2} \mathrm{O}_{2}$ and vitamin $\mathrm{C}$ on eryptosis among samples with G6PD deficiency or G6PD normal activity in vitro, the conclusion still needs to be confirmed in vivo. Finally, more specific and precise technologies are still required to qualify and quantify the process of eryptosis.

\section{Disclosure Statement}

The authors declare no commercial or financial conflict of interest.

\section{References}

1 Cappellini MD, Fiorelli G: Glucose-6-phosphate dehydrogenase deficiency. Lancet 2008;371:64-74. 


\section{Cellular Physiology Cell Physiol Biochem 2016;39:1453-1462

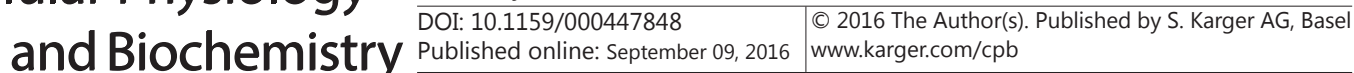 \\ Shan et al.: Vitamin C Protects G6PD Deficiency Erythrocytes}

2 Stanton RC: Glucose-6-phosphate dehydrogenase, NADPH, and cell survival. IUBMB Life 2012;64:362-369.

3 Jiang W, Yu G, Liu P, Geng Q, Chen L, Lin Q, Ren X, Ye W, He Y, Guo Y, Duan S, Wen J, Li H, Qi Y, Jiang C, Zheng Y, Liu C, Si E, Zhang Q, Tian Q, Du C: Structure and function of glucose-6-phosphate dehydrogenase-deficient variants in Chinese population. Hum Genet 2006;119:463-478.

4 Chiu DT, Zuo L, Chao L, Chen E, Louie E, Lubin B, Liu TZ, Du CS: Molecular characterization of glucose-6phosphate dehydrogenase (G6PD) deficiency in patients of Chinese descent and identification of new base substitutions in the human G6PD gene. Blood 1993;81:2150-2154.

5 Qasim N, Mahmood R: Diminution of Oxidative Damage to Human Erythrocytes and Lymphocytes by Creatine: Possible Role of Creatine in Blood. PLoS One 2015;10:e0141975.

6 Lang E, Qadri SM, Lang F: Killing me softly - suicidal erythrocyte death. Int J Biochem Cell Biol 2012;44:1236-1243.

7 Lang F, Lang E, Foller M: Physiology and pathophysiology of eryptosis. Transfus Med Hemother 2012;39:308-314.

8 Lang F, Abed M, Lang E, Foller M: Oxidative stress and suicidal erythrocyte death. Antioxid Redox Signal 2014;21:138-153.

9 Lang E, Lang F: Triggers, inhibitors, mechanisms, and significance of eryptosis: the suicidal erythrocyte death. Biomed Res Int 2015;2015:513518.

10 Lang E, Lang F: Mechanisms and pathophysiological significance of eryptosis, the suicidal erythrocyte death. Semin Cell Dev Biol 2015;39:35-42.

11 Dan B, Yang X, Yue P, Qingwei L: [Molecular regulations of phosphatidylserine eversion in plasma membrane]. Yi Chuan 2015;37:140-147.

12 Fontes JA, Banerjee U, Iazbik MC, Marin LM, Couto CG, Palmer AF: Effect of ascorbic acid on storage of Greyhound erythrocytes. Am J Vet Res 2015;76:789-800.

13 Sadowska-Bartosz I, Bartosz G: Ascorbic acid and protein glycation in vitro. Chem Biol Interact 2015;240:154-162.

14 Sureka C, Ramesh T, Begum VH: Attenuation of erythrocyte membrane oxidative stress by Sesbania grandiflora in streptozotocin-induced diabetic rats. Biochem Cell Biol 2015;93:385-395.

15 Rees DC, Kelsey H, Richards JD: Acute haemolysis induced by high dose ascorbic acid in glucose-6phosphate dehydrogenase deficiency. BMJ 1993;306:841-842.

16 Huang YC, Chang TK, Fu YC, Jan SL: C for colored urine: acute hemolysis induced by high-dose ascorbic acid. Clin Toxicol (Phila) 2014;52:984.

17 Tu H, Li H, Wang Y, Niyyati M, Wang Y, Leshin J, Levine M: Low Red Blood Cell Vitamin C Concentrations Induce Red Blood Cell Fragility: A Link to Diabetes Via Glucose, Glucose Transporters, and Dehydroascorbic Acid. EBioMedicine 2015;2:1735-1750.

18 Standardization of procedures for the study of glucose-6-phosphate dehydrogenase. Report of a WHO Scientific Group. World Health Organ Tech Rep Ser 1967;366:1-53.

19 Tang J, Jiang C, Xiao X, Fang Z, Li L, Han L, Mei A, Feng Y, Guo Y, Li H, Jiang W: Changes in red blood cell membrane structure in G6PD deficiency: an atomic force microscopy study. Clin Chim Acta 2015;444:264270.

20 Beutler E, Blume KG, Kaplan JC, Lohr GW, Ramot B, Valentine WN: International Committee for Standardization in Haematology: recommended screening test for glucose-6-phosphate dehydrogenase (G-6-PD) deficiency. Br J Haematol 1979;43:465-467.

21 Colosimo A, Guida V, De Luca A, Cappabianca MP, Bianco I, Palka G, Dallapiccola B: Reliability of DHPLC in mutational screening of beta-globin (HBB) alleles. Hum Mutat 2002;19:287-295.

22 Jiang WY, Zhou BY, Yu GL, Liu H, Zeng JB, Lin QD, Xi HL, Liang H: G6PD genotype and its associated enzymatic activity in a Chinese population. Biochem Genet 2012;50:34-44.

23 Souto RM, Laz MM, Reis RL: Degradation characteristics of hydroxyapatite coatings on orthopaedic TiAlV in simulated physiological media investigated by electrochemical impedance spectroscopy. Biomaterials 2003;24:4213-4221.

24 Jackson JB: A review of the binding-change mechanism for proton-translocating transhydrogenase. Biochim Biophys Acta 2012;1817:1839-1846.

25 Cimen MY: Free radical metabolism in human erythrocytes. Clin Chim Acta 2008;390:1-11. 


\section{Cellular Physiology Cell Physiol Biochem 2016;39:1453-1462 \begin{tabular}{ll|l} 
DOI: 10.1159/000447848 & $\begin{array}{l}\text { O 2016 The Author(s). Published by S. Karger AG, Basel } \\
\text { www.karger.com/cpb }\end{array}$
\end{tabular} \\ Shan et al.: Vitamin C Protects G6PD Deficiency Erythrocytes}

26 Rau MA, Whitaker J, Freedman JH, Di Giulio RT: Differential susceptibility of fish and rat liver cells to oxidative stress and cytotoxicity upon exposure to prooxidants. Comp Biochem Physiol C Toxicol Pharmacol 2004;137:335-342.

27 Li HT, Feng L, Jiang WD, Liu Y, Jiang J, Li SH, Zhou XQ: Oxidative stress parameters and anti-apoptotic response to hydroxyl radicals in fish erythrocytes: protective effects of glutamine, alanine, citrulline and proline. Aquat Toxicol 2013;126:169-179.

28 Sato Y, Kamo S, Takahashi T, Suzuki Y: Mechanism of free radical-induced hemolysis of human erythrocytes: hemolysis by water-soluble radical initiator. Biochemistry 1995;34:8940-8949.

29 Speckner W, Schindler JF, Albers C: Age-dependent changes in volume and haemoglobin content of erythrocytes in the carp (Cyprinus carpio L.). J Exp Biol 1989;141:133-149.

30 Sinha K, Das J, Pal PB, Sil PC: Oxidative stress: the mitochondria-dependent and mitochondria-independent pathways of apoptosis. Arch Toxicol 2013;87:1157-1180.

31 Ilmarinen P, Moilanen E, Kankaanranta H: Mitochondria in the center of human eosinophil apoptosis and survival. Int J Mol Sci 2014;15:3952-3969.

32 Bissinger R, Bouguerra G, Al Mamun Bhuyan A, Waibel S, Abbes S, Lang F: Efavirenz Induced Suicidal Death of Human Erythrocytes. Cell Physiol Biochem 2015;37:2496-2507.

33 Lang F, Qadri SM: Mechanisms and significance of eryptosis, the suicidal death of erythrocytes. Blood Purif 2012;33:125-130.

34 Bellows CF, Molina RM, Brain JD: Diminished organelle motion in murine Kupffer cells during the erythrocytic stage of malaria. J R Soc Interface 2011;8:711-719.

35 Castro M, Caprile T, Astuya A, Millan C, Reinicke K, Vera JC, Vasquez O, Aguayo LG, Nualart F: Highaffinity sodium-vitamin C co-transporters (SVCT) expression in embryonic mouse neurons. J Neurochem 2001;78:815-823.

36 Rumsey SC, Daruwala R, Al-Hasani H, Zarnowski MJ, Simpson IA, Levine M: Dehydroascorbic acid transport by GLUT4 in Xenopus oocytes and isolated rat adipocytes. J Biol Chem 2000;275:28246-28253.

37 Agus DB, Gambhir SS, Pardridge WM, Spielholz C, Baselga J, Vera JC, Golde DW: Vitamin C crosses the bloodbrain barrier in the oxidized form through the glucose transporters. J Clin Invest 1997;100:2842-2848.

38 Iwata N, Okazaki M, Xuan M, Kamiuchi S, Matsuzaki H, Hibino Y: Orally administrated ascorbic acid suppresses neuronal damage and modifies expression of SVCT2 and GLUT1 in the brain of diabetic rats with cerebral ischemia-reperfusion. Nutrients 2014;6:1554-1577.

39 Krukoski DW, Comar SR, Claro LM, Leonart MS, do Nascimento AJ: Effect of vitamin C, deferoxamine, quercetin and rutin against tert-butyl hydroperoxide oxidative damage in human erythrocytes. Hematology 2009;14:168-172.

40 Mansouri A, Lurie AA: Concise review: methemoglobinemia. Am J Hematol 1993;42:7-12.

41 Dawson EB, Harris WA, Powell LC: Relationship between ascorbic acid and male fertility. World Rev Nutr Diet 1990;62:1-26.

42 Netke SP, Roomi MW, Tsao C, Niedzwiecki A: Ascorbic acid protects guinea pigs from acute aflatoxin toxicity. Toxicol Appl Pharmacol 1997;143:429-435.

43 Vota DM, Maltaneri RE, Wenker SD, Nesse AB, Vittori DC: Differential erythropoietin action upon cells induced to eryptosis by different agents. Cell Biochem Biophys 2013;65:145-157.

44 Lang F, Gulbins E, Lang PA, Zappulla D, Foller M: Ceramide in suicidal death of erythrocytes. Cell Physiol Biochem 2010;26:21-28. 